$15^{\prime} 9^{\prime \prime}, 2 ; 32^{\prime} 5^{\prime \prime}, 9$, demnächst die Conj. $10^{\text {h }} 9^{\prime} 35^{\prime \prime}, 0+1,827$ d $)$. in Paris $3^{\text {h }} 21^{\prime} 36^{\prime \prime}, 1-1,869 \mathrm{~d} \Delta R$. und Länge $6^{\mathrm{h}} 47^{\prime} 43^{\prime \prime}, 3$.

April 10. III. Den Stern finde ich, aufser der hist. cél. *), noch zweimal in Bessel's Zonen 281: $7^{\text {h }} 4^{\prime} 8^{\prime \prime}, 83$; 336: $7^{\text {h }} 3^{\prime} 58^{\prime \prime}, 24$; da er hier um $0^{\prime \prime}, 7$ Zeit östlicher steht, als in der hist. eél., so habe ich diese neueren Beobachtungen zum Grunde gelegt, wonach der scheinbare Ort am Beobachlungstage wird $106^{\circ} 7^{\prime} 10^{\prime \prime}, 3+16^{\circ} 49^{\prime} 31^{\prime \prime}, 3$; des Mondes $105^{\circ} 54^{\prime} 52^{\prime \prime}, 8+16^{\circ} 39^{\prime} 59^{\prime \prime}, 6 ; 15^{\prime} 8^{\prime \prime}, 8 ; 32^{\prime} 5^{\prime \prime}, 3$ :

*) p. 255: 7h 2'27',5.
Conjunction um $10^{\text {h }} 21^{\prime} 32^{\prime \prime}, 6+1,513 \mathrm{dD}$., in Paris $\mathrm{um}$ $3^{\text {h }} 33^{\prime} 28^{\prime \prime}, 7-1,870$ dAR.; demnach Länge $6^{\text {h }} 47^{\prime} 50^{\prime \prime}, 4$.

Es stimmen demnach die Resultate

$\begin{array}{rr}\text { aus April 7 : } & 647^{\prime} 51,9 \\ 10 . \text { I. } & 44,9 \\ \text { 10. II. } & 43,3 \\ \text { 10. III. } & 50,4 \\ \text { Mittel : } & 64747,6\end{array}$

so gut überein, als nur zu wïnschen war; die beiden anderu veichen, wie oben bemerkt, aus mir unbekannten Ursachen sehr beträchtlich ab.

Mannheim 1829. Nov. 17.

\title{
Nachträge zu der Länge von Irkutzk.
}

I. Herr Professor Schwerd hat anf meine Bitte die Gefälligkeit gehabt, den Stern zu der ersten Bedeckung vom $8^{\text {ten }}$ Februar aufzusuchen; er hat am $7^{\text {ten }}$ Decbr. dessen scheinbaren Ort beobachtet:

$$
\text { 1h } 17^{\prime} 49^{\prime \prime}, 45 ;+6^{\circ} 33^{\prime} 1^{\prime \prime}, 4
$$

Ich habe daraus den scheinbaren Ort für den Tag der Bedeckung abgeleitet:

$$
19^{\circ} 26^{\prime} 29^{\prime \prime}, 0+6^{\circ} 32^{\prime} 40^{\prime \prime}, 4
$$

woraus ich, mit dem scheinbaren Mondorle $19^{\circ} 12^{\prime} 3^{\prime \prime}, 1$ $+6^{\circ} 24^{\prime} 45^{\prime \prime}, 0 ; 16^{\prime} 14^{\prime \prime}, 7$, der stïndlichen Bewegung $34^{\prime} 5^{\prime \prime}, 0$ und den Correctionen des Mondortes, welche die Altonaer Culminationen geben, die Länge erhalte

$$
6^{\text {h }} 47^{\prime} 36^{\prime \prime}, 6
$$

Mannleim 1829. Dec. 21.
II. Herr Professor Wurm, dem ich die beiden abweichenden Resultate Febr. 8. II, und April 9 mittheilte, war so gülig mit meinen Sternposilionen die Rechnung zu wiederholen; der Erfolg stimmte für Februar 8. II mit dem meinigen; bei April 9 hingegen fand ich den Fehler in meiner Interpolation des wahren Mondortes aus der conn. d. t., nach dessen Verbesserung die Bedeckung dieses Tages gibt $6^{\text {h }} 47^{\prime} 35^{\prime \prime}, 1$.

Das Mittel aus den 6 Bedeckungen, die 7te, Febr.8. 11, muls aufser Anschlag bleiben, ist demnach für die Länge von Irkutzk, Beobachtungsort des Herrn Prof. Hansteen, $6^{\text {h }} 47^{\prime} 43^{\prime \prime}, 8$

von welchem Mittel die Eẍtreme nicht über $\pm 8^{\prime \prime}$ abweichen. v. Heiligenstein.

\section{Bedeckung des Aldebaran am gten December 1829 auf der Sternwarte zu Mannheim und Speier} beobachtet.

Aus folgenden, von den Herren Prof. Nicolai und Schwerd mir gütigst mitgetheilten Beobachtungen:

$$
\begin{aligned}
& \text { Mannh. Sternzeit Eintr. } 23_{27}^{\text {h }} 47^{\prime \prime}, 2 \\
& \text { Austr. } \quad 0 \quad 28 \quad 1.4 \\
& \text { AR. app. Mond IR. } 433 \quad 50,60 \\
& \text { Speier — Eintr. } 232722,45 \\
& \text { Austr. } \quad 0 \quad 2740,93 \text { (39",93 ?) }
\end{aligned}
$$

Habe ich die Conjunctionen in AR. und wahrer Zeit hergeleitet:
Mannheim Einfr. $7^{\text {h }} 51^{\prime} 42,5+0,544 \mathrm{dD}$.

Austr. $\quad 44,4+0,232$

demnach dD. $=+6^{\prime \prime}, 09$ und of $7 \mathrm{~h}^{\prime} \mathrm{1}^{\prime} 45^{\prime \prime}, 8$

Speier Eintr. $7^{\mathrm{h}} 51^{\prime} 37^{\prime \prime}, 5+0,535 \mathrm{dD}$.

Austr. $\quad 39,1+0,242$

woraus $\mathrm{dD}=+5^{\prime \prime}, 46$ und $\sigma 7^{\mathrm{h}} 51^{\prime} 40^{\prime \prime}, 4$.

Diese Resultate stellen die bekannte Meridiandifferenz beider Sternwarten mit yorzüglicher Genauigkeit dar, wobei 